\title{
Morphological and Structural Study of Native Kidneys in Chronic Kidney Disease Patients on Dialysis Compared to Non-Dialysis Patients
}

\author{
Jacques Vigan ${ }^{*}$, Patricia Ahouansou Yekpe ${ }^{2}$, Sonia Adjanohoun², Séraphin Ahoui ${ }^{3}$, \\ Bruno Leopold Agboton'1, Hosana Kpoviessi SM1, Olivier Biaou²
}

${ }^{1}$ Nephrology and Hemodialysis Academic Clinic, National University Hospital Center, Hubert K Maga (CNHU-HKM) of

Cotonou, Cotonou, Benin

${ }^{2} \mathrm{CNHU}-\mathrm{HKM}$ Medical Imaging Center, Cotonou, Benin

${ }^{3}$ Nephrology Healthcare Center, Borgou Regional Hospital, Parakou, Benin

Email: *viques2@yahoo.fr

How to cite this paper: Vigan, J., Yekpe, P.A., Adjanohoun, S., Ahoui, S., Agboton, B.L., SM, H.K. and Biaou, O. (2020) Morphological and Structural Study of Native Kidneys in Chronic Kidney Disease Patients on Dialysis Compared to Non-Dialysis Patients. Open Journal of Nephrology, 10, 348-360.

https://doi.org/10.4236/ojneph.2020.104034

Received: October 26, 2020

Accepted: November 22, 2020

Published: November 25, 2020

Copyright $\odot 2020$ by author(s) and Scientific Research Publishing Inc. This work is licensed under the Creative Commons Attribution International License (CC BY 4.0).

http://creativecommons.org/licenses/by/4.0/

\begin{abstract}
Whether on dialysis or not, native kidneys in chronic kidney disease (CKD) patients undergo morphological and structural changes. Objective: To study native kidney morphometric and structural aspects in CKD patients on dialysis and non-dialysis patients. Methods: It was a descriptive, analytical, and cross-sectional study conducted from May to December 2018. The study enrolled CKD patients on dialysis or not followed at CNHU-HKM in Cotonou. Renal ultrasound was performed to locate cysts and uroscanner completed in the presence of atypical cysts. Through logistic regression, associated factors were determined. Results: The sample size was 240 patients, of which 151 (62.9\%) were receiving dialysis and 89 (37.1\%) non-dialysis patients. Male subjects were predominant (sex ratio $=1.5$ ). The average size of the right kidney, expressed in $\mathrm{mm}$ in patients on dialysis was: pole-to-pole length $=78.56$; width $=42.06$; cortical thickness $=11.80$; and the left kidney: pole-to-pole length $=79.76$; width $=41.53$; cortical thickness $=12.6$. For nondialysis patients, the following size was recorded for the right kidney: pole-to-pole length $=92.35$; width $=47.61$; cortical thickness $=15.64$; and left kidney: length $=92.13$; width $=47.82$; cortical thickness $=15.43$. Predictive factors for the occurrence of acquired renal cysts were: old age $(p=0.0001)$, dialysis $(\mathrm{p}<0.001)$ and diabetic nephropathy $(\mathrm{p}=0.0014)$. Conclusion: $\mathrm{CKD}$ patients on dialysis have small kidneys and are more likely to develop acquired renal cysts. There is a need to carry out an annual ultrasound screening for native kidneys in patients receiving dialysis.
\end{abstract}




\section{Keywords}

Chronic Kidney Disease, Dialysis, Acquired Renal Cysts

\section{Introduction}

Given its silent nature, chronic kidney disease is often diagnosed at the end stage [1]. According to the World Health Organization (WHO), End-Stage Chronic Kidney Disease (ESCKD) is currently the $12^{\text {th }}$ leading cause of death and the $17^{\text {th }}$ leading cause of morbidity in the world [2] [3]. It has been declared a major public health priority in many countries due to a steady increase in its incidence, prevalence, and its medico-social and economic consequences [4]. In Africa, ESCKD accurate prevalence is poorly documented. In Ivory Coast, it accounts for $5.8 \%$ of patients admitted to hospitals, of which only $5 \%$ have access to replacement therapy [5].

The only way of managing end-stage chronic kidney disease (ESCKD) is either through dialysis or kidney transplant (KT) [6]. In Benin, hemodialysis is the preferred treatment. In the long-run, patients on dialysis develop certain renal conditions including Acquired Cystic Kidney Disease (ACKD) and Renal Cell Carcinoma (RCC). Thus, in 1970, ACKD was recognized as a long-term consequence of dialysis [7].

Cancer registries have consistently reported high frequency of urogenital cancer, particularly Renal Cell Carcinoma (RCC) in CKD patients because they present risk factors for cancer; acquired cystic kidney disease being a well-known example [8]. Autopsy studies conducted on patients on dialysis suggest $33 \%$ and $0.6 \%$ prevalence for ACKD and RCC respectively [9]. An international multi-center study proved that, during an average follow-up period of 2.5 years, $3 \%$ of patients developed cancer [10]. Current data in the literature indicate that most patients will develop acquired renal cystic conditions after 3 to 7 years of dialysis, with $1.6 \%$ to $7 \%$ cases being associated with RCC [11]. ACKD is not described only in patients undergoing dialysis, but also in CKD non-dialysis patients. Thus, Meola et al. [12] reported in their study $8 \%-22 \%$ ACKD prevalence in CKD patients before dialysis.

As kidney transplant is not practiced in Benin, hemodialysis duration is longer compared to other countries. In addition, the relatively long seniority (10 - 20 years) of some patients, the huge number of patients receiving dialysis, and the free dialysis service constitute an ideal ground for describing the anomalies on native kidney of patients receiving dialysis. No study on long-term CKD complications of native kidneys has been performed to date in Benin. Given these circumstances, this study was initiated.

\section{Objectives}

\section{Main objective}


To study native kidney morphometric and structural aspects in chronic kidney disease patients on dialysis and non-dialysis patients.

\section{Specific objectives}

1) Compare native kidney morphometric and structural aspects in chronic kidney disease patients on dialysis to non-dialysis patients.

2) Identify the factors associated with the occurrence of acquired cystic kidney disease in chronic kidney disease patients undergoing dialysis.

\section{Study Framework and Methods}

This study was carried out in the Nephrology and Hemodialysis University Hospital (CUNH) and the Ultrasound and CT ScanServices of the medical imaging center within Hubert Koutoukou MagaNational Teaching Hospital (CNHU-HKM) located in Littoral region, Benin.

It was a single-center, descriptive, analytical and cross-sectional study conducted over an 8-month period from May to December 2018.

The study population was made up of CKD patients followed at CNHU/HKM Nephrology and Hemodialysis University Department. They were divided into two groups:

- $1^{\text {st }}$ group: comprising CKD patients receiving dialysis.

- $2^{\text {nd }}$ group: comprising CKD non-dialysis patients.

The study enrolled all patients aged over 15 years, diagnosed with CKD (Glomerular Filtration Rate according to the simplified MDRD formula $<60$ $\mathrm{ml} / \mathrm{min} / 1.73 \mathrm{~m}^{2}$ for at least 3 months); receiving dialysis or not; followed at CNHU/HKM Nephrology and Hemodialysis University Department and having given their consent to participate in the study.

We excluded patients with known history of cystic kidney disease: autosomal recessive polycystic kidney disease/autosomal dominant polycystic kidney disease, nephronophthisis, Joubert syndrome, Bardet-Biedl syndrome, Bourneville tuberous sclerosis, Von Hippel-Lindau disease, multicystic dysplastic kidney, unilateral cystic dystrophy. The same applies to patients on dialysis with renal cysts before receiving dialysis or subjects with solitary kidney.

Non-probability sampling was performed with a comprehensive survey of patients meeting our inclusion criteria.

The dependent variable was morphometric abnormalities in the kidney structure:

- Kidney dimensions.

- Presence of renal cysts.

The independent variables were as follows:

- Socio-demographic variables: age; sex; profession.

- Clinical variables in relation to the functional signs sought during the patient detailed interview (hematuria, lower back pain), personal health practices (tobacco); early kidney disease, medical history and Body Mass Index.

- Paraclinical variables included uremia, creatinine level, uric acid level, GFR, 
CKD stage, complete blood count, blood serum ionogram, serum calcium level, serum phosphate level, blood serum protein level, cholesterolemia, triglyceridemia. Only uremia and serum creatinine were determined in non-dialysis patients. For patients on dialysis, all samples were collected at the start of dialysis session and blood glucose, urea and creatinine levels were determined once again at the end of dialysis session.

- Variables in related to dialysis were: dialysis duration, frequency of dialysis, and percentage of urea reduction.

Patients meeting our criteria were seen individually. Interviews were carried out on dialysis days (for patients on dialysis) and during routine consultations (for non-dialysis patients). Each patient was interviewed, and then benefitted from a complete physical examination, lab tests and renal ultrasound. In addition, uroscan was performed for only dialysis patients with atypical cysts detected on ultrasound. Data was collected with a questionnaire designed for that purpose.

Ultrasound was performed with HITACHI EUB 5500 machine, by two different radiologists. The first is a radiologist with Advanced Degree in Medical Imaging and two years of experience in France prior to his recruitment at CNHU-HKM where he has been practicing for two years. The second was trained in France. The results were then confirmed by a radiologist, medical imaging professor.

SIEMENS SOMATOM Emotion 16 Barettes scanner was used. The renal cysts were detected through CT sections of the abdomen before and after intravenous injection of iodinated contrast. Having dismissed contraindications (iodine allergy), the iodine-based contrast was administered and all patients on dialysis received dialysis immediately after injection.

Patients participated in the study voluntarily and their identity was strictly protected. Each patient has given their informed consent. Data were entered with EPI-DATA software version 3.1. Data audit and analysis were performed with STATA/IC11.0 statistical software. Univariate and multivariate logistic regression analysis helped to determine associated factors. The significance level was set at $5 \%$ and confidence intervals estimated at $95 \%$.

\section{Results}

\subsection{General Characteristics of the Study Population}

A total of 240 patients met our criteria. They are categorized as follows: 151 (62.9\%) on dialysis and 89 (37.1\%) non-dialysis.

The patients mean age was $49.22 \pm 14.27$ years with 17 and 95 as extreme values. Men represented $60.80 \%$ of the study population, i.e. 146 , and women $39.20 \%$, i.e. 94 . Sex ratio was 1.5 .

In the population made up of non-dialysis patients, $16(18 \%)$ were at stage 3; $23(25.8 \%)$ at stage 4 and $50(56.2 \%)$ at stage 5 of CKD. Most patients on dialysis attended two weekly dialysis treatment sessions. Table 1 outlines the general 
Table 1. General characteristics of the study population.

\begin{tabular}{lc}
\hline & Values \\
\hline Mean age & $49.2 \pm 14.2$ years \\
Male & $60.8 \%$ \\
Hypertension & $92.9 \%$ \\
Diabetes milletus & $15.0 \%$ \\
Humain Immunodéficiency Virus & $2.5 \%$ \\
viral Hepatitis B & $2.9 \%$ \\
viral Hepatitis C & $5.0 \%$ \\
Tabacco & $3.3 \%$ \\
Morbid obesity & $1.3 \%$ \\
Severe obesity & $2.5 \%$ \\
Moderate obesity & $6.7 \%$ \\
Overweight & $16.3 \%$ \\
Two hemodialysis sessions/week & $96.7 \%$ \\
Three hemodialysis sessions/week & $3.3 \%$ \\
Age on dialysis $<3$ years & $45.0 \%$ \\
Age on dialysis between $[3][10]$ (years) & $42.4 \%$ \\
Age on dialysis $\geq 10$ years & $12.6 \%$ \\
Percentage of ureareduction $>60 \%$ & $84.1 \%$ \\
\hline
\end{tabular}

characteristics of the sample.

\subsection{Native Kidney Morphometric and Structural Aspects in Chronic Kidney Disease Patients on Dialysis Compared to Non-Dialysis Patients}

\subsubsection{Morphometric Aspects}

A statistically significant difference was established between the renal size of patients on dialysis and non-dialysis patients $(\mathrm{p}<0.001)$, regardless of the side of the kidney. Table 2 outlines renal size comparative mean values and standard deviations of patients on dialysis and non-dialysis patients.

\subsubsection{Structural Aspects}

Almost all patients on dialysis (96.69\%) had dedifferentiated kidneys. Out of 151 patients on dialysis, the frequency of hospital attendance as a result of acquired renal cysts was $58.94 \%$. Moreover, $58.43 \%$ of them had simple cyst while atypical cysts accounted for $41.57 \%$. Table 3 outlines the distribution of patients on dialysis according to Bosniak classification. Bosniak type III is the most common. Figure 1 and Figure 2 show the pictures.

The majority of non-dialysis patients (53.93\%) had differentiated kidneys. Out of 89 non-dialysis patients, 27 had renal cysts which account for $30.34 \%$ hospital frequency. Simple and atypical cysts accounted for $85.19 \%$ and $14.81 \%$ respectively. 
Table 2. Comparison of values mean and standard deviations of renal dimensions (in $\mathrm{mm}$ ), number and size of cysts of hemodialysis patients with those of non-dialysis patients.

\begin{tabular}{lcccc}
\hline \multirow{2}{*}{$\begin{array}{c}\text { Hemodialysis } \\
\text { patients }\end{array}$} & \multicolumn{2}{c}{ RIGHT KIDNEY } & \multicolumn{2}{c}{ LEFT KIDNEY } \\
\cline { 2 - 5 } & Mean & Standard deviation & Mean & Standard deviation \\
\hline Length & 78.56 & 14.96 & 79.76 & 15.89 \\
Width & 42.06 & 9.93 & 41.53 & 9.49 \\
Cortical thickness & 11.80 & 3.63 & 12.67 & 2.90 \\
& 1.85 & & 2.02 & \\
Number of cysts & 1.01 & & 1.07 & \\
& 11.00 & & 16.27 & \\
Size of cysts (mm) & 7.63 & & 6.72 & \\
& & & & \\
Non-dialysis patients & 92.35 & 12.15 & 92.13 & \\
Length & 47.61 & 8.16 & 47.82 & 3.35 \\
Width & 15.64 & 3.58 & 15.43 & \\
Cortical thickness & 1.20 & & 1.41 & \\
& 0.52 & & 0.79 & \\
Number of cysts & & & 15.25 & \\
Size of cysts (mm) & 19.0211 .23 & & 8.17 & \\
\hline
\end{tabular}

Table 3. Distribution of hemodialysis patients with atypical cysts according to the Bosniak classification.

\begin{tabular}{ccccc}
\hline & \multicolumn{2}{c}{ RIGHT KIDNEY } & \multicolumn{2}{c}{ LEFT KIDNEY } \\
\cline { 2 - 5 } & $\begin{array}{c}\text { Effective } \\
(\mathrm{n}=37)\end{array}$ & Percentage $(\%)$ & $\begin{array}{c}\text { Effective } \\
(\mathrm{n}=31)\end{array}$ & $\begin{array}{c}\text { Percentage } \\
(\%)\end{array}$ \\
\hline Bosniak type I & 4 & 10.8 & 3 & 9.7 \\
Bosniak type II & 3 & 8.1 & 2 & 6.4 \\
Bosniak type IIF & 4 & 10.8 & 5 & 16.2 \\
Bosniak type III & 23 & 62.2 & 19 & 61.3 \\
Bosniak type IV & 3 & 8.1 & 2 & 6.4 \\
\hline
\end{tabular}

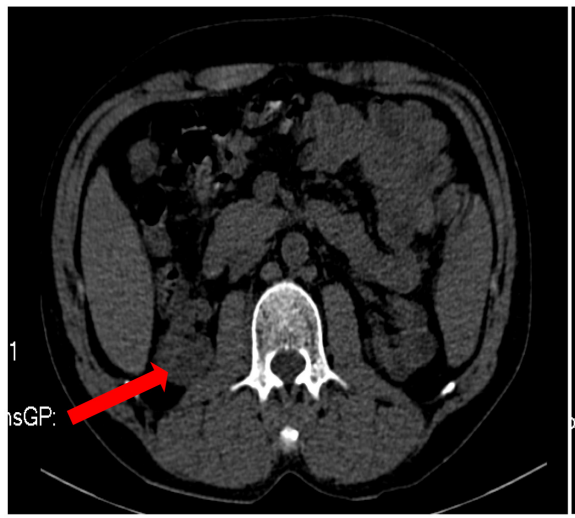

(a)

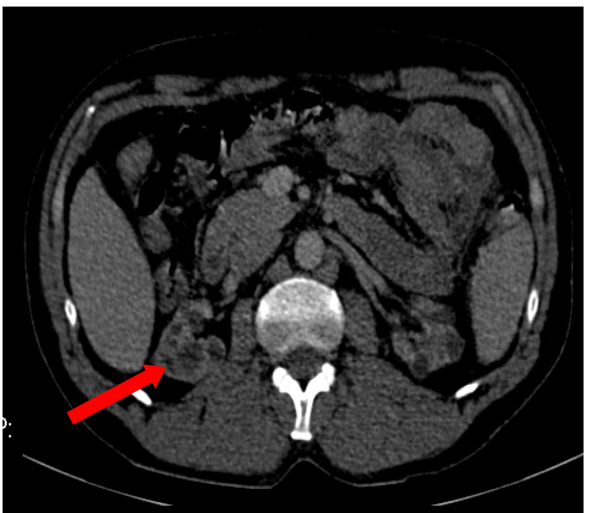

(b)

Figure 1. Bilateral renal cystic formations with thick walls and irregular contours with thick septa classified Bosniak type III (red arrowhead indicates the lesions described). (a) Before injection of contrast product. (b) After injection of contrast product. 


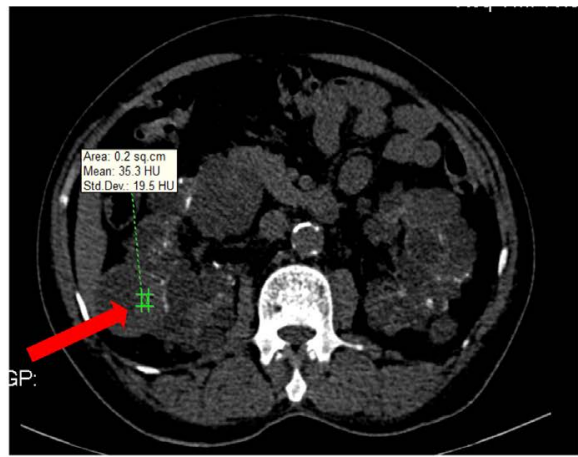

(a)

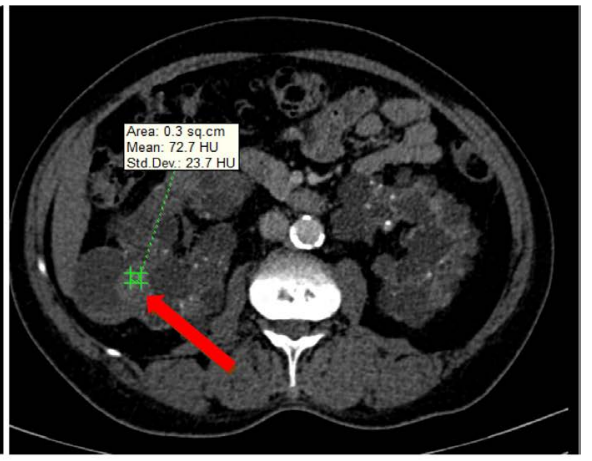

(b)

Figure 2. Bilater alrenal multicysts with a tissue component on the right (red arrow) clearly enhancing after injection of contrast product classified Bosniak type IV. (a) Before injection of contrast product. (b) After injection of contrast product.

The average cyst size in patients on dialysis was $19.02 \mathrm{~mm}$ with extreme values of 8 and $36 \mathrm{~mm}$ on the right, while on the left, $15.25 \mathrm{~mm}$ was recorded with extreme values of 8 and $33 \mathrm{~mm}$. For non-dialysis patients, the average cyst size was $11 \mathrm{~mm}$ with extreme values of 4 and $32 \mathrm{~mm}$ on the right, while on the left 16.27 $\mathrm{mm}$ was recorded with extreme values of 4 and $25 \mathrm{~mm}$.

Patients on dialysis had a higher average number of cysts in the right and left kidneys than non-dialysis patients, respectively in the corresponding kidneys with a statistically significant difference $(p=0.006$ on the right and $p=0.03$ on the left). The average cyst size is higher in the left kidney of patients on dialysis than non-dialysis patients, however, the difference is insignificant ( $p=0.7$ on the left).

\subsection{Factors Associated with Acquired Renal Cysts in Patients on Dialysis}

In univariate analysis, age is associated with cysts in patients on dialysis ( $\mathrm{p}=$ $0.005)$ and the risk of developing cysts increases with age. Diabetes $(p=0.019)$ and diabetic nephropathy $(\mathrm{p}=0.017)$ are equally associated and appear to be protective factors. Furthermore, dialysis $(\mathrm{p}<0.001)$ and the seniority of dialysis $(\mathrm{p}<0.001)$ are associated. Patients on dialysis are more than 3 times likely to develop cysts on their native kidneys, and this risk increases with the seniority of dialysis. Table 4 outlines the factors associated with renal cysts in univariate analysis.

Following multivariate analysis, 3 factors were found to be predictive for the occurrence of cysts in the study population. They included: old age ( $p=0.0001)$, dialysis $(\mathrm{p}<0.001)$ and diabetic nephropathy $(\mathrm{p}=0.0014)$ as shown in Table 5 .

\section{Discussion}

\subsection{Morphometric and Structural Aspects of Native Kidneys in Chronic Kidney Disease Patients on Dialysis Compared to Non-Dialysis Patients}

\subsubsection{Morphometric Aspects}

This study revealed that the average pole-to-pole kidney length in patients on 
Table 4. Associated factors with renal cysts in hemodialysis patients in univariate analysis.

\begin{tabular}{|c|c|c|c|c|}
\hline & $\begin{array}{l}\text { Cysts } \\
\text { n (\%) }\end{array}$ & $\begin{array}{c}\text { No cysts } \\
\text { n (\%) }\end{array}$ & RC [IC-95\%] & $\mathrm{P}$ \\
\hline \multicolumn{5}{|l|}{ Age } \\
\hline$<40$ & $14(35.9)$ & $25(64.1)$ & 1 & \multirow{4}{*}{0.005} \\
\hline$[40-50]$ & $29(60.4)$ & $19(39.6)$ & $2.72[1.13-6.52]$ & \\
\hline$[50-60]$ & $32(71.1)$ & $13(28.9)$ & $4.39[1.75-11.01]$ & \\
\hline$\geq 60$ & $14(73.7)$ & $5(26.32)$ & $4.99[1.48-16.81]$ & \\
\hline \multicolumn{5}{|c|}{ Diabetes milletus } \\
\hline No & $83(62.4)$ & $50(37.6)$ & 1 & \multirow{2}{*}{0.019} \\
\hline Yes & $6(33.3)$ & $12(66.7)$ & $0.30[0.11-0.85]$ & \\
\hline \multicolumn{5}{|c|}{ Diabetic nephropathy } \\
\hline No & $84(62.2)$ & $51(37.8)$ & 1 & \multirow{2}{*}{0.017} \\
\hline Yes & $5(31.3)$ & $11(68.7)$ & $0.27[0.09-0.84]$ & \\
\hline \multicolumn{5}{|l|}{ Hemodialysis } \\
\hline No & $27(30.34)$ & $62(69.66)$ & 1 & \multirow{2}{*}{$<0.001$} \\
\hline Yes & $89(58.94)$ & $62(41.06)$ & $3.29[1.89-5.74]$ & \\
\hline \multicolumn{5}{|c|}{ Seniority in dialysis (years) } \\
\hline$<3$ & $24(35.3)$ & $44(64.7)$ & 1 & \multirow{3}{*}{$<0.001$} \\
\hline$[3-10]$ & $47(73.4)$ & $17(26.6)$ & $5.06[2.40-10.67]$ & \\
\hline$\geq 10$ & $18(94.7)$ & $1(5.3)$ & $33[4.14-262.61]$ & \\
\hline
\end{tabular}

Table 5. Prédictive factors of the occurrence of renal cysts in hemodialysis patients.

\begin{tabular}{ccccc}
\hline & $\begin{array}{c}\text { Cysts } \\
\mathrm{n}(\%)\end{array}$ & $\begin{array}{c}\text { OR raw } \\
{[\mathrm{CI}(95 \%)]}\end{array}$ & $\begin{array}{c}\text { OR adjusted } \\
{[\mathrm{CI}(95 \%)]}\end{array}$ & Value $\mathrm{p}$ \\
\hline $\begin{array}{c}\text { Age (years) } \\
<40\end{array}$ & $14(35.9)$ & 1 & 1 & 0.0001 \\
{$[40-50]$} & $29(60.4)$ & $2.72[1.13-6.52]$ & $2.36[1.08-5.11]$ & \\
{$[50-60]$} & $32(71.1)$ & $4.39[1.75-11.01]$ & $4.96[2.17-11.33]$ & \\
$\geq 60$ & $14(73.7)$ & $4.99[1.48-16.81]$ & $5.68[2.25-14.32]$ & \\
Hemodialysis & & & & $<0.001$ \\
No & $27(30.34)$ & 1 & 1 & \\
Yes & $89(58.94)$ & $3.29[1.89-5.74]$ & $4.05[2.12-7.75]$ & \\
Diabetic nephropathy & & & & 0.0014 \\
No & $84(62.2)$ & 1 & 1 & \\
Yes & $5(31.3)$ & $0.27[0.09-0.84]$ & $0.24[0.10-0.60]$ & \\
\hline
\end{tabular}

OR = Odds Ratio; RC ajusted = ajusted fordialysis, age; diabetic nephropathy; Value p khi-carré of Wald; IC $(95 \%)=$ Confidence interval at $95 \%$.

dialysis was $78.56 \pm 14.96 \mathrm{~mm}$ and $79.76 \pm 15.89 \mathrm{~mm}$ for the right kidney (RK) and left kidney (LK) respectively. These sizes were similar to those recorded by Agboton et al. [13] in 2015 in Benin, which were $76.7 \pm 22 \mathrm{~mm}$ on the right and $76.9 \pm 2 \mathrm{~mm}$ on the left respectively. 
The average renal width in this study $(\mathrm{RK}=42.06 \pm 9.93 \mathrm{~mm}$; $\mathrm{LK}=41.53 \pm$ $9.49 \mathrm{~mm}$ ) was greater than the size recorded by Agboton et al. [13] in his study $(\mathrm{RK}=30.2 \pm 11.5 \mathrm{~mm} ; \mathrm{LK}=29.1 \pm 10.2 \mathrm{~mm}$ ). This difference could be related to the exclusion of patients with diabetic nephropathy in Agboton et al. sample [13].

As for cortical thickness, the measured values in this study $(\mathrm{RK}=11.80 \mathrm{~mm}$; $\mathrm{LK}=12.67 \mathrm{~mm}$ ) were also greater than the figures reported by Agboton et al. [13] $(\mathrm{RK}=8.5 \mathrm{~mm} ; \mathrm{LK}=8.6 \mathrm{~mm})$. Our values exceeded those of Beland et al. [14] $(\mathrm{RK}=5.9 \mathrm{~mm} ; \mathrm{LK}=5.9 \mathrm{~mm})$. These authors underlined the existence of a strong correlation between cortical thickness values and the progress of nephropathy. According to Agboton et al., cortical thickness thinning remains the most reliable index for assessing chronic kidney disease [13].

The pole-to-pole kidney length recorded in CKD non-dialysis patients varied between $59-130 \mathrm{~mm}$ and $59-132 \mathrm{~mm}$ for the right and left kidney respectively. These sizes match with those of Ahoui et al. [15] who reported $58-119 \mathrm{~mm}$ and $60-120 \mathrm{~mm}$ for the right and left kidney respectively. The average pole-to-pole kidney length in our study was $92.35 \mathrm{~mm}$ and $92.13 \mathrm{~mm}$ for the right and left kidney respectively. These values are close to those presented by Makusidi et al. [16] who recorded $91.1 \pm 10.6 \mathrm{~mm}$ and $92.3 \pm 10.7 \mathrm{~mm}$ respectively. Savi de Tove et al. [1] reported $84.83 \mathrm{~mm}$ as average pole-to-pole kidney length, which is lower than the value recorded in this study.

The renal width measured in this study $(\mathrm{RK}=24-77 \mathrm{~mm}$; LK $=27-87 \mathrm{~mm}$ ) was close to the size recorded by Ahoui et al. [15] in northern Benin ( $\mathrm{RK}=25$ $69 \mathrm{~mm}$; LK $=26-67 \mathrm{~mm}$ ). In Serbia, Jovanović et al. [17] reported mean values estimated at $47 \pm 8 \mathrm{~mm}$ and $47.8 \pm 10.3 \mathrm{~mm}$ for the right and left kidney respectively.

The average cortical thickness values measured in this study were $15.64 \pm 3.58$ $\mathrm{mm}$ and $15.43 \pm 3.29 \mathrm{~mm}$ on the right and left respectively. These values are significantly higher than those recorded by Beland et al. [14] in Island and Moghazi et al. [18] in the United States, who reported $5.9 \mathrm{~mm}$ and $8.3 \mathrm{~mm}$ respectively as a mean cortical thickness.

The average values of all renal parameters $(\mathrm{mm})$ measured on ultrasound were respectively greater in non-dialysis patients than patients on dialysis. Renal hypotrophy, much more prevalent in end-stage chronic kidney disease patients on dialysis may be due to the seniority of impaired renal function.

\subsubsection{Structural Aspects}

- Corticomedullary differentiation

In the present series, $46.07 \%$ of CKD non-dialysis patients had dedifferentiated kidneys, while almost all i.e. $96.69 \%$ of patients on dialysis had dedifferentiated kidneys. Savi de Tove et al. reported that 52 out of 53 chronic kidney disease patients, i.e. 98.1\%, had hyperechoic dedifferentiated kidneys [1].

- Acquired renal cysts prevalence

In this study, acquired renal cysts prevalence was $58.94 \%$ in the population on 
dialysis and $30.34 \%$ in non-dialysis patients. Several other authors reported the same higher prevalence in patients on dialysis than non-dialysis patients. In the United States, Matson et al. [19] reported in their study that acquired renal cysts prevalence was less than $7 \%$ before dialysis, however, it could reach $80 \%$ in patients having received dialysis for 10 years. Méola et al. [12] in Italy, also asserted that this prevalence was approximately $8 \%$ to $22 \%$ in CKD non-dialysis patients and could reach $100 \%$ in subjects having received dialysis for over 10 years.

In Japan. Kojima et al. [20] reported $81.8 \%$ as acquired renal cysts prevalence in patients on dialysis; which is significantly higher than the figure recorded in this study. Denton et al. [9] in the United States and Gnionsahe et al. [21] in Ivory Coast published $33 \%$ and $31 \%$ respectively as the prevalence in chronic dialysis patients.

ACKD prevalence in patients with End Stage Renal Disease (ESRD) varies between $30 \%$ and $90 \%$, depending on the type of investigation: autopsy, ultrasound, CT scan, clinical investigations [9].

- Number and size of cysts

The cysts reported in this study were more in patients on dialysis than non-dialysis patients, regardless of the side of the kidney. This finding is consistent with the observation made by several other authors who described acquired renal cysts as a "multiple small bilateral cysts" [12]. Correas et al. [22] concluded that the size of acquired renal cysts developed by patients on dialysis was less than $20 \mathrm{~mm}$. Rahbari-Oskoui et al. [23] also described acquired renal cysts as "multiple small bilateral cysts". On the other hand, Mensel et al. reported $15 \mathrm{~mm}$ as the size in male patients in the general population, and 1.8 as the average number of renal cysts [24].

- Types of cysts

Per renal ultrasound revealed in patients on dialysis that, simple cysts were predominantly represented (58.43\%) compared to atypical cysts (41.57\%). The rates of type III and IV (represented by Figure 1 and Figure 2) in this study are alarmingly higher than those of Schwarz et al. [25] in Germany who reported $8.2 \%$ frequency for types IIF and III, while type IV was estimated at $1.5 \%$. It's worth noting that these authors conducted their study on a particular population: patients on dialysis who received kidney transplant.

\subsection{Factors Associated with Acquired Renal Cystsin Patients on Dialysis}

A statistically significant relationship was established between the age of patients on dialysis and the occurrence of acquired renal cysts $(p=0.005)$. Older patients are more likely to develop cysts. Several authors such as Scandling [26] and Schwarz et al. [25] have also pointed out old age as a factor associated with acquired renal cysts occurrence in patients on dialysis. However, other researchers reported data which provided contradictory evidence in relation to this study. That is the case of Nahm et al. who did not observe a correlation between age and acquired renal cysts occurrence [27]. In this study, old age appears to be a 
predictor of acquired renal cysts occurrence in patients on dialysis.

A statistically significant association was established between acquired renal cyst occurrence and diabetes $(p=0.019)$. Diabetes had a protective effect on renal cysts occurrence in patients on dialysis. Unlike data reported in this study, Schwarz et al. [25] did not observe any statistically significant relationship between diabetes and acquired renal cysts occurrence.

A statistically significant relationship was established between diabetic nephropathy and acquired renal cysts occurrence $(\mathrm{p}=0.017)$. Diabetic nephropathy had a beneficial effect on cysts occurrence $(\mathrm{OR}=0.27$ [0.09-0.84]). Other authors reported low prevalence of cysts in patients with diabetic nephropathy [28].

In this study, dialysis is associated with acquired renal cysts occurrence ( $\mathrm{p}<$ 0.001). Although not a causal factor, dialysis appears to be a factor which is associated with the occurrence of acquired renal cysts. It is equally considered as a predictive factor in the genesis of acquired renal cysts.

In the present study, $73.4 \%$ of patients with 3 to 9 years of dialysis and $94.7 \%$ of subjects with at least 10 years of dialysis developed acquired renal cysts. These patients were respectively 5.06 and 33 times more likely to develop acquired renal cysts than patients with less than 3 years of dialysis. The current literature also indicates that many patients will develop acquired renal cysts after 3 to 7 years of dialysis [11]. Matson et al. [13] also report that after 3 to 5 years on dialysis, 50\% of patients develop acquired renal cysts. According to Farivar-Mohseni et al. [29], the major predisposing factor to ACKD is the prolonged duration of dialysis; actually, the disease occurs in $40 \%$ to $60 \%$ of patients with 3 to 5 years of dialysis and $90 \%$ of subjects with 5 to 10 years or more. For Truong et al., ACKD occurs in $13 \%-50 \%$ and $87 \%$ respectively after 2.6 and 9 years of dialysis and $100 \%$ of patients after 10 years [30].

\section{Conclusions}

CKD patients on dialysis have smaller kidneys than non-dialysis patients. They develop multiple kidney cysts. Acquired renal cysts are more widespread in patients on dialysis than non-dialysis patients regardless of the side of the kidney, while cyst size seems to be smaller in patients on dialysis. Atypical cysts are less common than simple cysts. It is worth noting the predominance of type III cysts in atypical cysts according to Bosniak classification.

Predictive factors for acquired renal cysts occurrence were: old age, dialysis and diabetic nephropathy. It is important to organize an annual follow-up of native kidneys in hemodialysis patients.

\section{Conflict of Interest Declaration}

The authors declare no conflicts of interest regarding the publication of this paper.

\section{References}

[1] Savi de Tove, K.M., Biaou, O., Mobima, T., Yekpe, P. and Boco, V. (2015) Longueur 
et échogénicité rénale dans l'insuffisance rénale à Parakou. Journal Africain d'Imagerie Médicale, 4, 208-216.

[2] National Kidney Foundation (2002) K/DOKI Clinical Practice Guideline for Chronic Kidney Disease: Evaluation, Classification and Stratification. American Journal of Kidney Disease, 39, S1-266.

[3] Levey, A.S., Eckardt, K.-U., Tsukamoto, Y., Levin, A., Coresh, J., et al. (2005) Definition and Classification of Chronic Kidney Disease: A Position Statement from Kidney Disease; Improving Global Outcomes (K/DIGO). Kidney International, 67, 2089-2100. https://doi.org/10.1111/j.1523-1755.2005.00365.x

[4] Robert Atkins, C. (2005) The Epidemiology of Chronic Kidney Disease. Kidney International, 67, 14-18. https://doi.org/10.1111/j.1523-1755.2005.09403.x

[5] Diallo, A., Niamkey, E. and Beda, Y. (1997) L'insuffisance rénale chronique en Côte d'Ivoire: étude de 800 cas hospitalisés. Bulletin de la Société de Pathologie Exotique, 90, 346-348.

[6] Levey, A.S. and Coresh, J. (2012) Chronic Kidney Disease. The Lancet, 379, 165-180. https://doi.org/10.1016/S0140-6736(11)60178-5

[7] Dunnill, M.S., Millard, P.R. and Oliver, D. (1977) Acquired Cystic Disease of the Kidneys: A Hazard of Long-Term Intermittent Maintenance Haemodialysis. Journal of Clinical Pathology, 30, 868-877. https://doi.org/10.1136/jcp.30.9.868

[8] Holley, J.L. (2007) Screening, Diagnosis, and the Treatment of Cancer in Long-Term Dialysis Patients. Clinical Journal of the American Society of Nephrology, 2, 604-610. https://doi.org/10.2215/CJN.03931106

[9] Denton, M.D., Magee, C.C., Ovuworie, C., Mauiyyedi, S., Pascual, M., Colvin, R.B., et al. (2002) Prevalence of Renal Cell Carcinoma in Patients with ESRD Pre-Transplantation: A Pathologic Analysis. Kidney International, 61, 2201-2209. https://doi.org/10.1046/j.1523-1755.2002.00374.x

[10] Maisonneuve, P., Agodoa, L., Gellert, R., Stewart, J.H., Buccianti, G., Lowenfels, A.B., et al. (1999) Cancer in Patients on Dialysis for End-Stage Renal Disease: An International Collaborative Study. The Lancet, 354, 93-99. https://doi.org/10.1016/S0140-6736(99)06154-1

[11] Ishikawa, I. (1991) Acquired Cystic Disease: Mechanisms and Manifestations. Seminars in Nephrology, 11, 671-684.

[12] Meola, M., Samoni, S. and Petrucci, I. (2016) Clinical Scenarios in Chronic Kidney Disease. Kidneys' Structural Changes in End-Stage Renal Disease. ContribNephrol. Basel, Karger, 188, 131-143. https://doi.org/10.1159/000445475

[13] Agboton, B., Yepke, P., Vigan, J., Gandji, S., Kloussa, E., Aguemon, B., et al. (2014) Biométrie rénale de l'adulte béninois apparemment sain. JAMO, 3, 18-23.

[14] Beland, M.D., Walle, N.L., Machan, J.T. and Cronan, J.J. (2010) Renal Cortical Thickness Measured at Ultrasound: Is It Better than Renal Length as an Indicator of Renal Function in Chronic Kidney Disease? American Journal of Roentgenology, 195, 146-149. https://doi.org/10.2214/AJR.09.4104

[15] Ahoui, S., Vigan, J., Dovonou, C.A., Savi de tove, K.M., Agboton, B.L., Koba, G.A.K.K., et al. (2016) Etude de la morphologie des reins chez les insuffisants rénaux chroniques par échographie au centre hospitalier universitaire départemental du borgou (chud/b). Cahiers du CBRST, 9, 1-10.

[16] Makusidi, M.A., Chijioke, A., Braimoh, K.T., Aderibigbe, A., Olanrewaju, T.O. and Liman, H.M. (2014) Usefulness of Renal Length and Volume by Ultrasound in Determining Severity of Chronic Kidney Disease. Saudi Journal of Kidney Diseases 
and Transplantation, 25, 1117-1121. https://doi.org/10.4103/1319-2442.139981

[17] Jovanović, D., Gasic, B., Pavlovic, S. and Naumovic, R. (2013) Correlation of Kidney Size with Kidney Function and Anthropometric Parameters in Healthy Subjects and Patients with Chronic Kidney Diseases. Renal Failure, 35, 896-900. https://doi.org/10.3109/0886022X.2013.794683

[18] Moghazi, S., Jones, E., Schroepple, J., Arua, K., McClellan, W., Hennigar, R.A., et al. (2005) Correlation of Renal Histopathology with Sonographic Findings. Kidney International, 67, 1515-1520. https://doi.org/10.1111/j.1523-1755.2005.00230.x

[19] Matson, M.A. and Cohen, E.P. (1990) Acquired Cystic Kidney Disease: Occurrence, Prevalence, and Renal Cancers. Medicine (Baltimore), 69, 217-226. https://doi.org/10.1097/00005792-199007000-00003

[20] Kojima, Y., Takahara, S., Miyake, O., Nonomura, N., Morimoto, A. and Mori, H. (2006) Renal Cell Carcinoma in Dialysis Patients: A Single Center Experience. International Journal of Urology, 13, 1045-1048. https://doi.org/10.1111/j.1442-2042.2006.01498.x

[21] Gnionsahe, D.A., Lagou, D.A. and Tia, W.M. (2007) Prevalence of Acquired Cystic disease in Black Africans on Hemodialysis in West Africa. Saudi Journal of Kidney Diseases and Transplantation, 18, 114-116.

[22] Correas, J.-M., Joly, D., Chauveau, D., Richard, S. and Hélénon, O. (2011) Insuffisance rénale et maladies kystiques du rein. Journal de Radiologie, 92, 308-322. https://doi.org/10.1016/j.jradio.2011.02.021

[23] Rahbari-Oskoui, F. and O’Neill, W.C. (2017) Diagnosis and Management of Acquired Cystic Kidney Disease and Renal Tumors in ESRD Patients. Seminars in Dialysis, 30,373-379. https://doi.org/10.1111/sdi.12605

[24] Mensel, B., Kuhn, J.P., Kracht, F., Volzke, H., Lieb, W., Dabers, T., et al. (2018) Prevalence of Renal Cysts and Association with Risk Factors in a General Population: An MRI-Based Study. Abdominal Radiology, 43, 3068-3074. https://doi.org/10.1007/s00261-018-1565-5

[25] Schwarz, A., Vatandaslar, S., Merkel, S. and Haller, H. (2007) Renal Cell Carcinoma in Transplant Recipients with Acquired Cystic Kidney Disease. Clinical Journal of the American Society of Nephrology, 2, 750-756. https://doi.org/10.2215/CJN.03661106

[26] Scandling, J.D. (2007) Acquired Cystic Kidney Disease and Renal Cell Cancer after Transplantation: Time to Rethink Screening? Clinical Journal of the American Society of Nephrology, 2, 621-622. https://doi.org/10.2215/CJN.02000507

[27] Nahm, A.-M. and Ritz, E. (2001) Acquired Renal Cysts. Nephrology Dialysis Transplantation, 16, 1506-1508. https://doi.org/10.1093/ndt/16.7.1506

[28] Concolino, G., Lubrano, C., Ombres, M., Santonati, A., Flammia, G.P. and di Silverio, F. (1993) Acquired Cystic Disease: The Hormonal Hypothesis. Urology, 41, 170-175. https://doi.org/10.1016/0090-4295(93)90175-A

[29] Farivar-Mohseni, H., Perlmutter, A.E., Wilson, S., Shingleton, W.B., Bigler, S.A. and Fowler Jr., J.E. (2006) Renal Cell Carcinoma and End Stage Renal Disease. Journal of Urology, 175, 2018-2020. https://doi.org/10.1016/S0022-5347(06)00340-5

[30] Truong, L.D., Choi, Y.-J., Shen, S.S., Ayala, G., Amato, R. and Krishnan, B. (2003) Renal Cystic Neoplasms and Renal Neoplasms Associated with Cystic Renal Diseases: Pathogenetic and Molecular Links. Advances in Anatomic Pathology, 10, 135-159. https://doi.org/10.1097/00125480-200305000-00003 